\title{
Antimicrobial resistance and characterisation of staphylococci isolated from healthy Labrador retrievers in the United Kingdom
}

Vanessa M Schmidt ${ }^{1,6^{*}+}$, Nicola J Williams ${ }^{2+}$, Gina Pinchbeck ${ }^{2 \dagger}$, Caroline E Corless ${ }^{3 \dagger}$, Stephen Shaw ${ }^{4 \dagger}$, Neil McEwan ${ }^{1,6+}$, Susan Dawson ${ }^{2+}$ and Tim Nuttall ${ }^{5+}$

\begin{abstract}
Background: Coagulase-positive (COPS) and coagulase-negative (CoNS) staphylococci are normal commensals of the skin and mucosa, but are also opportunist pathogens. Meticillin-resistant (MR) and multidrug-resistant (MDR) isolates are increasing in human and veterinary healthcare. Healthy humans and other animals harbour a variety of staphylococci, including MR-CoPS and MR-CoNS. The main aims of the study were to characterise the population and antimicrobial resistance profiles of staphylococci from healthy non-vet visiting and non-antimicrobial treated Labrador retrievers in the UK.

Results: Nasal and perineal samples were collected from 73 Labrador retrievers; staphylococci isolated and identified using phenotypic and biochemical methods. They were also confirmed by matrix-assisted laser desorption ionisation time-of-flight mass spectrometry (MALDI-TOF-MS), PCR of the nuc gene and PCR and sequencing of the tuf gene. Disc diffusion and minimum inhibitory concentration (MIC) susceptibility tests were determined for a range of antimicrobials. In total, 102 CoPS (S. pseudintermedius $n=91$, S. aureus $n=11$ ) and 334 CoNS isolates were detected from $99 \%$ of dogs in this study. In $52 \%$ of dogs CoNS only were detected, with both CoNS and CoPS detected in $43 \%$ dogs and CoPS only detected in $4 \%$ of dogs. Antimicrobial resistance was not common among CoPS, but at least one MDR-CoNS isolate was detected in 34\% of dogs. MR-CoNS were detected from $42 \%$ of dogs but no MR-CoPS were isolated. S. epidermidis (52\% of dogs) was the most common CoNS found followed by $S$. warneri (30\%) and S. equorum (27\%), with another 15 CoNS species isolated from $\leq 15 \%$ of dogs. S. pseudintermedius and $\mathrm{S}$. aureus were detected in $44 \%$ and $8 \%$ of dogs respectively.
\end{abstract}

Conclusions: MR- and MDR-CoPS were rare. However a high prevalence of MR- and MDR-CoNS were found in these dogs, even though they had no prior antimicrobial treatment or admission to veterinary premises. These findings are of concern due to the potential for opportunistic infections, zoonotic transmission and transmission of antimicrobial resistant determinants from these bacteria to coagulase positive staphylococci.

Keywords: Coagulase-postive staphylococci, Coagulase-negative staphylococci, Meticillin-resistant, Dogs, MALDI-TOF-MS, Tuf gene, Nuc gene, Antimicrobial-susceptibility

\footnotetext{
* Correspondence: v.schmidt@liv.ac.uk

${ }^{\dagger}$ Equal contributors

'Department of Infection Biology, The University of Liverpool, Leahurst

Campus, Neston, UK

${ }^{6}$ The University of Liverpool School of Veterinary Science, Leahurst Campus,

Chester High Road, Neston, Wirral CH64 7TE, UK

Full list of author information is available at the end of the article
} 


\section{Background}

Staphylococci are normal commensal bacteria of the skin and mucous membranes of humans and other animals. They can be differentiated by their ability to produce coagulase, with coagulase positive (CoPS) staphylococci regarded as more pathogenic than coagulase negative (CoNS) species [1-5].

Healthy humans and other animals may harbour multiple species and strains of staphylococci. Staphylococcus aureus is the main human commensal CoPS species and is carried in the nasal cavity of approximately $30 \%$ of healthy people [6]. S. epidermidis is the most common CoNS isolated from the nares, perineum, inguinal skin, axillae and interdigital skin in man [2,7]. The main commensal CoPS of dogs, S. pseudintermedius [8], has been isolated from $37 \%$ to $92 \%$ of healthy dogs [9-14], while S. aureus is carried by $4.3 \%$ to $12 \%$ of healthy dogs $[10,12,15-20]$. Other species isolated from the mucosa and skin of healthy dogs include the CoPS S. schleiferi subspecies coagulans $[10,21]$ and numerous CoNS ( $S$. schleiferi subspecies schleiferi, S. epidermidis, S. haemolyticus, S. saprophyticus, S. devriesei, S. warneri, S. simulans, S. xylosus, S.capitus, S. caprae, and S. sciuri) [12,15,22-26]. The carriage rate of CoNS isolated from the nasal mucosae of healthy dogs was reported to be $38 \%$ in one large cross-sectional study [15].

Staphylococci are frequent opportunistic pathogens and commensal isolates are the most common source of infection in humans [3] and dogs [12,16,27]. Antimicrobial resistance can increase the morbidity, mortality and treatment cost of staphylococcal infections. Meticillin (oxacillin) resistance associated with carriage of the mecA gene confers resistance to all $\beta$-lactam antimicrobials [28]. The $m e c \mathrm{~A}$ gene is located on a large mobile genetic element, the staphylococcal cassette chromosome mec (SCCmec), enabling horizontal transmission between staphylococcal isolates [29]. Meticillin resistant staphylococci (MRS) are important pathogens in human and veterinary healthcare and are often multi-drug resistant (MDR; resistant to three or more classes of antimicrobial) [30-35], extremely limiting therapeutic options. MRSP clones with a broader resistance spectrum than MRSA or MR-CoNS are increasingly reported in domestic animals throughout Europe, USA and Canada [32,34]. MR-CoNS are associated with infections in humans and animals [31,36-38]. In humans the most prevalent species is MR S. epidermidis (MRSE), which may be a reservoir of MR for $S$. aureus $[39,40]$. In addition, the SCCmec cassette of the major European MRSP clone (ST71-J-t02-II-III) [34] consists of a combination of SCCmec II from MRSE and SCCmec III from MRSA [41].

The prevalence of MRSA and MRSP carriage in healthy humans and dogs in the community is low [11,18,36,42-47]. However, human community-based surveys report a wider range of carriage rates for MRCoNS $(11-50 \%)[39,48,49]$. MR-CoNS have also been isolated from the carriage sites of $13 \%$ of healthy dogs [23,50]. The reported prevalence of MRS is higher in animals exposed to veterinary healthcare environments and antimicrobial therapy [47,51-53] suggesting that these are risk factors for colonisation.

Previous studies looking at the commensal staphylococci in dogs have concentrated on CoPS species, particularly MR-CoPS species, the CoNS group or MR-CoNS species $[9-11,13,14,17,23,50]$, but no study has characterised the complete canine commensal staphylococcal population. Moreover, reporting of the antimicrobial treatment history of dogs in these studies have been inconsistent. The aim of this study was to characterise the mucosal staphylococcal population structure and antimicrobial resistance profiles in healthy Labrador retrievers in the UK in the absence of antimicrobial pressure. This will be important in understanding changes in staphylococcal populations and their antimicrobial susceptibility patterns in dogs exposed to antimicrobials and other risk factors.

\section{Methods}

\section{Study population}

Labrador retriever dogs were recruited for the study from dog shows in the UK between November 2010 and June 2011. One healthy dog was enrolled from each household if the dog had not received topical or systemic antimicrobial therapy, or had not been admitted to a veterinary clinic within the last 12 months. All dog owners gave written informed consent before enrolment in this study and completed a questionnaire regarding potential risk factors for the carriage of antimicrobial resistant bacteria. The University of Liverpool School of Veterinary Science ethics committee approved the study protocol.

\section{Staphylococci}

\section{Specimen collection and bacterial isolation}

One nasal swab and one perineal swab were collected from each dog (Copan Eswab LQ Amies Minitip Nylon Flocked Applicator, Appleton Woods, Birmingham, UK). A sterile swab was either inserted $5 \mathrm{~mm}$ into one nostril or rubbed on the skin of the perineum for 3-5 seconds before being placed in Amies transport media, stored at $4{ }^{\circ} \mathrm{C}$ and processed within 36 hours. Swabs were incubated aerobically overnight at $37^{\circ} \mathrm{C}$ in nutrient broth with $6.5 \%$ sodium chloride. The broth was streaked onto mannitol salt agar (MSA), oxacillin resistance screening agar (ORSA) supplemented with $2 \mu \mathrm{g} / \mathrm{ml}$ of oxacillin and Columbia 5\% horse blood agar (CAB), and incubated aerobically overnight at $37^{\circ} \mathrm{C}$. Where present, isolates typical of staphylococci were selected from all plates, subcultured onto $\mathrm{CAB}$ and incubated aerobically overnight at $37^{\circ} \mathrm{C}$. Fresh staphylococcal cultures on $\mathrm{CAB}$ were subject 
to Gram stain (Sigma-Aldrich Company Ltd., Gillingham, UK), tested for catalase (Sigma-Aldrich Company Ltd., Gillingham, UK) and free coagulase production (Rabbit plasma, Pro-Lab, Bromborough, UK) according the manufacturer's instructions and stored at $-80^{\circ} \mathrm{C}$ in Microbank vials (Pro-Lab, Bromborough, UK). All media were obtained from LabM Ltd, Bury, UK.

\section{Antimicrobial susceptibility testing}

Disc diffusion testing was performed on all staphylococcal isolates in accordance with the Clinical and Laboratory Standards Institute (CLSI) and the following panel of ten antimicrobial discs were applied: $1 \mu \mathrm{g}$ oxacillin (OX), $1 \mu \mathrm{g}$ ciprofloxacin (CIP), $10 \mu \mathrm{g}$ gentamicin (GM), $10 \mu \mathrm{g}$ fusidic acid (FA), $30 \mu \mathrm{g}$ cefalexin (CFX), $30 \mu \mathrm{g}$ cefovecin $(\mathrm{CVN}), 25 \mu \mathrm{g}$ trimethoprim-sulfamethoxazole (TS), $10 \mu \mathrm{g}$ tetracycline (Tet), $2 \mu \mathrm{g}$ clindamycin (CD) and $5 \mu \mathrm{g}$ vancomycin (Va) [54]. All the discs were purchased from MAST Group Ltd., Liverpool, UK, except for CVN, which were obtained from Oxoid, Basingstoke, UK. Micro-dilution susceptibility testing (Trek Diagnostic Systems, Cleveland, Ohio, USA) was performed on a subset of the CoNS isolates using the same antimicrobial panel, except vancomycin [54]. Interpretation was based on the CLSI guidelines for animal species-specific zone diameter $(\mathrm{mm})$ interpretive standards and minimal inhibitory concentration (MIC; $\mathrm{mg} / \mathrm{l}$ ) breakpoints for veterinary pathogens or human-derived interpretive standards when available. The European Committee on Antimicrobial Susceptibility Testing (EUCAST) zone diameter interpretive standards and MIC breakpoints were used for CIP and FA [55]. The breakpoints used for interpretation of OX resistance were a zone of inhibition of $\leq 17 \mathrm{~mm}$ and MIC $\geq$ $0.5 \mathrm{mg} / \mathrm{l}$ for S. pseudintermedius and CoNS, and $\leq 10 \mathrm{~mm}$ and $\mathrm{MIC} \geq 4 \mathrm{mg} / \mathrm{l}$ for $S$. aureus [56,57]. The breakpoints used for interpretation of resistance to $\mathrm{CVN}$ as a zone of inhibition of $\leq 19 \mathrm{~mm}$ and MIC $\geq 8 \mathrm{mg} / \mathrm{l}$ in accordance with the manufacturer's recommendations. The reference strain S. aureus ATCC 25923 (LGC Standards, Teddington, UK) was used for quality control for MIC and zone diameter determinations.

\section{DNA extraction}

Three colonies of each staphylococcal isolate were homogenised in $90 \mu \mathrm{l}$ of sterile distilled water (SDW) and $10 \mu \mathrm{l}$ of lysostaphin $(1 \mathrm{mg} / \mathrm{ml}$; Sigma-Aldrich Company Ltd., Gillingham, UK) and vortexed for 5 seconds. The suspensions were then incubated at $37^{\circ} \mathrm{C}$ for $10 \mathrm{mi}-$ nutes and heated at $100^{\circ} \mathrm{C}$ for 10 minutes before adding $400 \mu \mathrm{l}$ of SDW. Samples were stored at $4^{\circ} \mathrm{C}$.

\section{Characterisation of antimicrobial resistance genes}

PCR assays were performed to detect the presence of mecA gene (Table 1) in staphylococcal isolates that were phenotypically resistant to oxacillin. All the PCR assays were performed with $0.5 \mu \mathrm{l}$ of each primer $(10 \mathrm{pmol} / \mu \mathrm{l})$, $1 \mu \mathrm{l}$ of DNA and 1.1x PCR master mix (ReddyMix ${ }^{\mathrm{mm}}$, Thermo Fisher Scientific Inc., Surrey, UK) made up to a total reaction volume of $25 \mu \mathrm{l}$. Molecular grade water (Sigma-Aldrich Company Ltd., Gillingham, UK) was used as the negative control in all PCR assays. PCR products were analysed by agarose gel $(1.5 \%)$ electrophoresis and the DNA fragments were visualised under UV light after ethidium bromide staining.

\section{Species identification \\ Genotypic species identification}

PCR assays to detect the presence of the nuc genes of $S$. pseudintermedius, S. aureus and S. schleiferi were performed on all CoPS isolates using Qiagen ${ }^{\circ}$ Multiplex PCR Mix (Qiagen, Crawley, UK), according to the manufacturer's instructions with minor modifications. In short, the PCR assays were performed in a reaction volume of $25 \mu \mathrm{l}$, consisting of $5 \mu \mathrm{l}$ of bacterial DNA extract, $12.5 \mu \mathrm{l}$ of master mix, $2.5 \mu \mathrm{l}$ of $10 \mathrm{x}$ primer mix $(2 \mu \mathrm{M}$ of each primer) and $5 \mu \mathrm{l}$ of RNase-free water. The cycling conditions consisted of an initial activation step at $95^{\circ} \mathrm{C}$ for 15 minutes, followed by 30 cycles of $95^{\circ} \mathrm{C}$ for 30 seconds, $57^{\circ} \mathrm{C}$ for 90 seconds and $72^{\circ} \mathrm{C}$ for 60 seconds, and a final extension step at $72^{\circ} \mathrm{C}$ for 10 minutes (Table 1).

\section{MALDI-TOF-MS}

All isolates were subjected to matrix-assisted laser desorption ionisation time-of-flight mass spectrometry (MALDITOF-MS) according to the manufacturer's protocol. Raw spectra were analysed by the MALDI Biotyper 2.0 software programme with default settings (Bruker Daltonics, Bremen, Germany). The extraction method was performed as previously described [58] on overnight colonies grown on $\mathrm{CAB}$ at $37^{\circ} \mathrm{C}$ and all isolates were tested in duplicate. The bacterial test standard (E. coli DH5 alpha, Bruker, Bremen, Germany) was used for calibration before each experiment and included in duplicate on each target plate. The mass peak profiles were matched to the reference database and a score generated based on similarity [59].

\section{Sequencing}

Two subsets of isolates detected from our group of dogs underwent sequencing following PCR amplification of the tuf gene [59,60]; a control group of CoNS isolates $(n=27)$ identified by MALDI-TOF-MS and a test group of isolates $(\mathrm{n}=52)$ that had not been identified by MALDI-TOF-MS. Initial PCR assays were performed using HotStarTaq ${ }^{\circ}$ Master Mix Kit (Qiagen, Crawley, UK) in a $25 \mu$ reaction volume with an initial activation step at $95^{\circ} \mathrm{C}$ for $15 \mathrm{mi}$ nutes followed by 35 cycles of $95^{\circ} \mathrm{C}$ for 30 seconds, $55^{\circ} \mathrm{C}$ for 30 seconds and $72^{\circ} \mathrm{C}$ for 30 seconds, with a final 
Table 1 Details of PCR assays used in this study for nuc, tuf and mecA gene identification

\begin{tabular}{|c|c|c|c|c|c|}
\hline Primer & Sequence $\left(5^{\prime}-3^{\prime}\right)$ & $\begin{array}{l}\text { Amplicon } \\
\text { size (bp) }\end{array}$ & $\begin{array}{l}\text { Annealing } \\
\text { Temperature }\left({ }^{\circ} \mathrm{C}\right)\end{array}$ & Control strain & Reference \\
\hline au-F3 & TCGCTTGCTATGATTGTGG & \multirow[t]{2}{*}{359} & \multirow[t]{2}{*}{57} & \multirow{2}{*}{$\begin{array}{l}\text { S. aureus ATCC } 25923 \text { (LGC Standards, } \\
\text { Teddington, UK) }\end{array}$} & \multirow[t]{6}{*}{ [77] } \\
\hline au-nucR ${ }^{*}$ & GCCAATGTTCTACCATAGC & & & & \\
\hline pse-F2 & TRGGCAGTAGGATTCGTTAA & \multirow[t]{2}{*}{926} & \multirow[t]{2}{*}{57} & \multirow[t]{2}{*}{ S. pseudintermedius (clinical isolate) } & \\
\hline pse- $-R 5^{*}$ & CTITGTGCTYCMTITTGG & & & & \\
\hline SSnucF & AATGGCTACAATGATAATCACTAA & \multirow[t]{2}{*}{526} & \multirow[t]{2}{*}{57} & \multirow{2}{*}{$\begin{array}{l}\text { S. schleiferi subspecies coagulans } \\
\text { ATCC } 49545\end{array}$} & \\
\hline SSnucR* & CATATCTGTCTTTCGGCGCG & & & & \\
\hline tuf-F & GCCAGTTGAGGACGTATTCT & \multirow[t]{2}{*}{412} & \multirow[t]{2}{*}{55} & \multirow[t]{2}{*}{ S. epidermidis ATCC ${ }^{\oplus 12228}$} & \multirow[t]{2}{*}[105]{} \\
\hline tuf-R & CCATTTCAGTACCTTCTGGTAA & & & & \\
\hline mecAF & TGGCTATCGTGTCACAATCG & \multirow[t]{2}{*}{310} & \multirow[t]{2}{*}{55} & \multirow[t]{4}{*}{ MRSA (clinical isolate) } & \multirow[t]{4}{*}[103,104]{} \\
\hline mecAR & CTGGAACTTGTTGAGCAGAG & & & & \\
\hline mA1 & TGCTATCCACCCTCAAACAGG & \multirow[t]{2}{*}{286} & \multirow[t]{2}{*}{57} & & \\
\hline $\mathrm{mA2}$ & AACGTTGTAACCACCCCAAGA & & & & \\
\hline
\end{tabular}

(*multiplex assay).

extension step of $72^{\circ} \mathrm{C}$ for 5 minutes according to the manufacturer's protocol. The resulting amplicons were sequenced using BigDye Terminator version 1.1 cycle sequencing (Applied Biosystems, Foster City, CA, USA) according to the manufacturer's protocol on the ABI3131 genetic analyser at the Department of Microbiology, Royal Liverpool University Hospital. The sequences were aligned using the ABI Sequencing analysis software, with contiguous sequences matched to the GenBank database using the Basic Local Alignment Search Tool (BLAST) [61] and positively identified if there was $\geq 98 \%$ sequence similarity with a reference sequence. S. epidermidis ATCC ${ }^{\circledR} 12228$ was used as the control strain.

\section{Statistical analysis}

Data were analysed using SPSS software package (SPSS 20.0 for Mac, SPSS Inc, Chicago, Illinois).

To examine the association between isolation of $S$. pseudintermedius with each of the 16 different CoNS species Pearson's chi-square was calculated $(P<0.003$; Bonferroni correction). To examine the association between MR and MDR with potential risk factors (previous antimicrobial therapy or hospitalisation within 12 months of enrolment, health-care or large animal-association by in-contact people or pets) identified from the questionnaires Pearson's chi-square was calculated $(P<0.0125$; Bonferroni correction). To examine the agreement between antimicrobial susceptibility tests by disc diffusion and MIC a kappa statistic was calculated [62] and an independent $t$-test was conducted to compare the MIC of oxacillin resistant CoNS isolates that were either positive or negative for the mecA gene.

\section{Results}

Staphylococci

Specimen collection

Seventy-three Labrador retriever dogs were recruited. Twenty-one dogs were aged between 3 to 12 months, 25 dogs were aged between 12 months to 2 years, and 27 dogs were $>2$ years old, with 35 female dogs and 38 male dogs in total.

\section{Bacterial isolation}

Staphylococci were isolated from in 72 out of 73 dogs (99\%; 95\% confidence interval (CI): 99.6-95.8) and from both sample sites in the majority of dogs (78\%; 95\% CI: $67.3,86.0)$. Isolation of staphylococci from the nasal mucosae $(16 \%, 95 \%$ CI $9.7,26.6)$ or perineum $(4 \%, 95 \%$ CI $1.4,11.4$ ) only occurred in a small number of dogs. If only the nasal mucosae had been sampled, CoPS (all $S$. pseudintermedius) would not have been detected in seven dogs $(10 \%, 95 \%$ CI 4.7, 18.5) and CoNS in six dogs (8\%, 95\% CI 3.8, 16.8). CoNS were detected in the majority of dogs $(95 \%, 95 \%$ CI 86.7, 97.8) either alone $(52 \%$, 95\% CI 40.8, 63.1) or with CoPS (43\%, 95\% CI 31.8, 53.9). Detection of CoPS alone was significantly less common (4\%, 95\% CI 1.4, 11.4). In total, there were 436 staphylococcal isolates; 102 of which were CoPS and 334 were CoNS isolates.

\section{Antimicrobial susceptibility testing by disc diffusion}

The overall prevalence of antimicrobial resistance among the isolates detected in this study appeared high, with at least one MDR isolate detected in 34\% of dogs. Antimicrobial resistant CoNS isolates were detected in more dogs than antimicrobial resistant CoPS isolates for OX, 
GM, FA, CFX, CVN and CD and MDR (Figure 1). At least one OX resistant isolate was detected in $58 \%$ dogs ( $\mathrm{n}=126$ oxacillin resistant isolates), but resistance to the other tested $\beta$-lactam antimicrobials, CVN (25\%) and CFX (29\%), was less common. Few CoPS demonstrated antimicrobial resistance; isolates from twelve dogs had Tet resistance (all S. pseudintermedius), seven with FA resistance (S. pseudintermedius $=5, S$. aureus $=3$ ); two with TS resistance (both $S$. pseudintermedius); two with $\mathrm{CD}$ resistance $(S$. pseudintermedius $=1, S$. aureus $=1$ ) and two with CIP resistance (both $S$. pseudintermedius). MDR CoPS was detected from only one dog (S. pseudintermedius with FA, Tet and CD resistance) (Figure 1).

\section{MIC compared to disc diffusion testing for}

\section{antimicrobial resistance}

Micro-dilution susceptibility testing (Trek Diagnostic Systems, Cleveland, Ohio, USA) was performed on 172 CoNS isolates, of which 52 were OX susceptible and 120 were OX resistant by disc diffusion. The OX resistant isolates were further divided into those found to be positive $(n=74)$ or negative $(n=46)$ for carriage of the mecA gene by PCR. The strength of agreement between antimicrobial resistance detected by MIC and disc diffusion was very good for OX, GM, CVN, Tet and CD resistance, good for CFX and TS resistance and moderate for CIP $($ Kappa $=0.593)$ and FC resistance $($ Kappa $=0.589)$. MIC testing identified more isolates as resistant to OX, GM, CFX, CVN and Tet compared to disc diffusion, and disc diffusion identified more isolates as resistant to CIP, FA, TS and CD compared to MIC testing (Table 2).

\section{Characterisation of antimicrobial resistance genes}

Of the 126 OX resistant CoNS isolates detected by disc diffusion, 75 isolates $(60 \%, 95 \%$ CI 51, 68) from 31 dogs $(42 \%, 95 \%$ CI 32,54$)$ were positive for the mecA gene (Figure 1). Nine additional oxacillin resistant isolates were detected by MIC and two of these were positive for the mecA gene, resulting in two additional dogs with MR-CoNS and one additional dog with phenotypic oxacillin resistant CoNS. There was a significant difference between the MIC of mecA positive $(\mathrm{M}=3.84, \mathrm{SD}=0.18)$ and mecA negative isolates $(\mathrm{M}=0.97, \mathrm{SD}=0.12, P<0.001)$. In addition the epidemiological breakpoint for OX resistant CoNS isolates with mecA gene carriage isolated in this study was consistent with the clinical CLSI breakpoint $(\geq 0.5 \mathrm{mg} / \mathrm{l})$ (Figure 2). Eleven different CoNS species (S. epidermidis, S. warneri, S. sciuri, S. equorum, S. fleurettii,

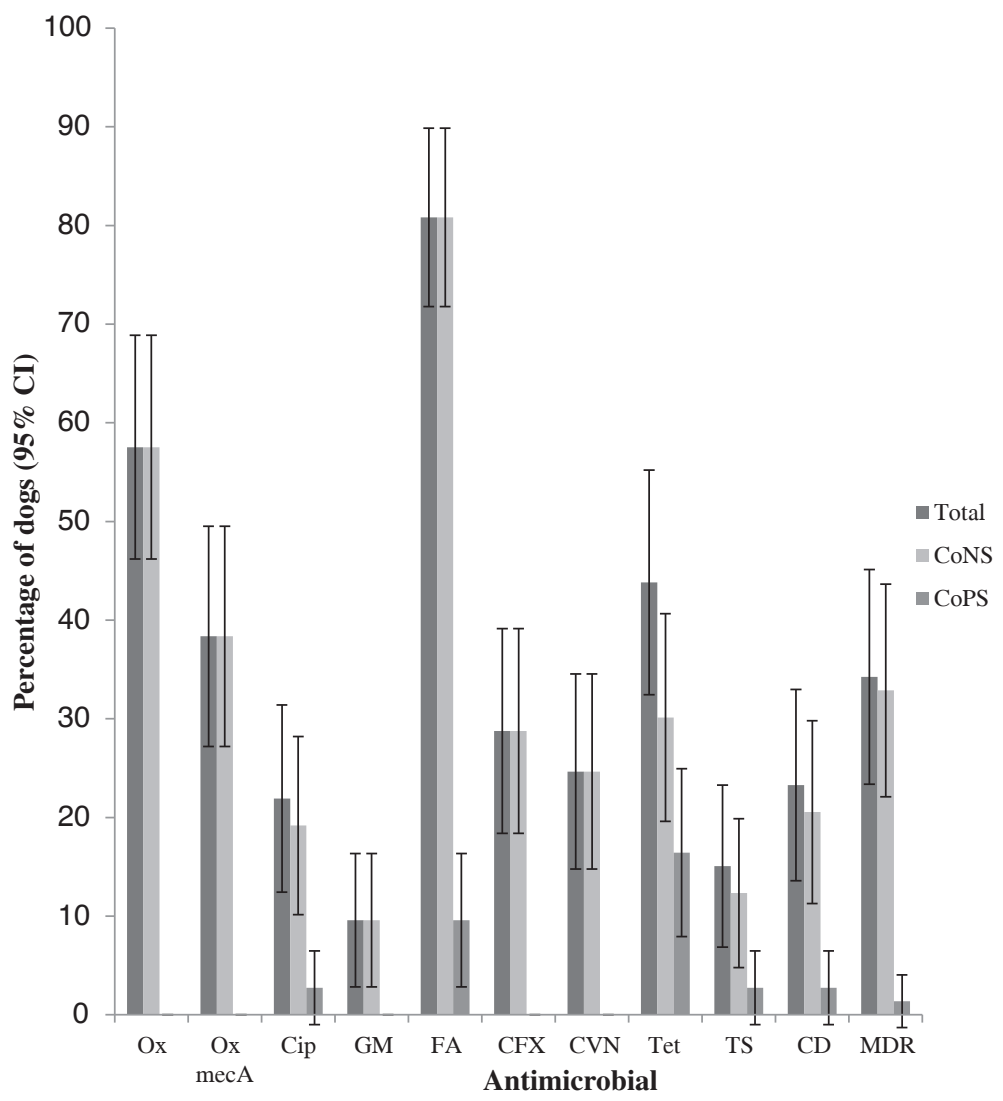

Figure 1 The proportion of dogs $(n=73)$ carrying at least one staphylococcal isolate with resistance to each antimicrobial, MDR and mecA gene positive oxacillin resistance by the disc diffusion method. Total = CoNS and CoPS. 
Table 2 Cross tabulation of the results of 172 staphylococcal isolates classified as resistant or susceptible to the antimicrobials tested in this study by both MIC and disc diffusion testing

\begin{tabular}{|c|c|c|c|c|c|}
\hline \multirow{2}{*}{$\begin{array}{l}\text { Antimicrobial } \\
\text { resistance }\end{array}$} & & & \multicolumn{3}{|l|}{ MIC } \\
\hline & & & No & Yes & Total \\
\hline \multirow[t]{5}{*}{ Oxacillin (OX) } & Disc diffusion & No & 50 & 10 & 60 \\
\hline & & Yes & 2 & 110 & 112 \\
\hline & & Total & 52 & 120 & 172 \\
\hline & & Kappa $=0.842$ & & & \\
\hline & & & No & Yes & Total \\
\hline \multirow{5}{*}{$\begin{array}{l}\text { Oxacillin mecA } \\
\text { positive }\end{array}$} & & No & 115 & 0 & 115 \\
\hline & & Yes & 1 & 56 & 57 \\
\hline & & Total & 116 & 56 & 172 \\
\hline & & Kappa $=0.987$ & & & \\
\hline & & & No & Yes & Total \\
\hline \multirow[t]{5}{*}{ Ciprofloxacin (CIP) } & & No & 146 & 0 & 157 \\
\hline & & Yes & 14 & 12 & 15 \\
\hline & & Total & 160 & 12 & 172 \\
\hline & & Kappa $=0.593$ & & & \\
\hline & & & No & Yes & Total \\
\hline \multirow[t]{5}{*}{ Gentamicin (GM) } & & No & 156 & 1 & 157 \\
\hline & & Yes & 0 & 15 & 15 \\
\hline & & Total & 156 & 16 & 172 \\
\hline & & Kappa $=0.965$ & & & \\
\hline & & & No & Yes & Total \\
\hline \multirow[t]{5}{*}{ Fusidic acid (FA) } & & No & 36 & 5 & 41 \\
\hline & & Yes & 25 & 106 & 131 \\
\hline & & Total & 61 & 111 & 172 \\
\hline & & Kappa $=0.589$ & & & \\
\hline & & & No & Yes & Total \\
\hline \multirow[t]{5}{*}{ Cefalexin (CFX) } & & No & 117 & 15 & 132 \\
\hline & & Yes & 0 & 40 & 40 \\
\hline & & Total & 117 & 55 & 172 \\
\hline & & Kappa $=0.784$ & & & \\
\hline & & & No & Yes & Total \\
\hline \multirow[t]{5}{*}{ Cefovecin (CVN) } & & No & 130 & 11 & 141 \\
\hline & & Yes & 0 & 31 & 31 \\
\hline & & Total & 130 & 42 & 172 \\
\hline & & Kappa $=0.810$ & & & \\
\hline & & & No & Yes & Total \\
\hline \multirow[t]{4}{*}{ Tetracycline (T10) } & & No & 148 & 1 & 149 \\
\hline & & Yes & 0 & 23 & 23 \\
\hline & & Total & 148 & 24 & 172 \\
\hline & & Карра $=0.975$ & & & \\
\hline
\end{tabular}

Table 2 Cross tabulation of the results of 172 staphylococcal isolates classified as resistant or susceptible to the antimicrobials tested in this study by both MIC and disc diffusion testing (Continued)

\begin{tabular}{lllll}
\hline & & & Yes & Total \\
$\begin{array}{l}\text { Trimethoprim- } \\
\text { sulfamethoxazole (TS) }\end{array}$ & No & 156 & 2 & 158 \\
& Yes & 3 & 11 & 14 \\
& Total & 159 & 13 & 172 \\
& Kappa $=0.799$ & & & \\
& & No & Yes & Total \\
Clindamycin (CD) & No & 148 & 2 & 150 \\
& Yes & 4 & 18 & 22 \\
& Total & 152 & 20 & 172 \\
& Kappa $=0.837$ & & & \\
\hline
\end{tabular}

S. vitulinus, S. saprophyticus, S. haemolyticus, S. lentus, S. succinus and $S$. pettenkoferi) were found to carry the mecA gene. Among oxacillin resistant CoNS species, $S$ epidermidis and S. sciuri were more likely to carry the mecA gene than S. saprophyticus, S. equorum, S. vitulinus and S. succinus (Figure 3). MRSE isolates were detected in 18 dogs (25\%, 95\% CI 14.8, 34.5), meticillin-resistant S. warneri were detected in 7 dogs $(10 \%, 95 \%$ CI $2.8,16.3)$ and meticillinresistant S. sciuri were detected in 5 dogs (7\%, 95\% CI 1.1, 12.6). The remaining species were only isolated from one or two dogs. MDR mecA positive CoNS were detected in 19 dogs $(26 \%, 95 \%$ CI 17.3, 37.1). There was no significant association between detection of MR-CoNS or MDR isolates and potential risk factors tested in this study (Pearson's chi-square; $P<0.0125$ ).

\section{Species identification}

Phenotypic and biochemical methods identified 436 isolates as Staphylococcus species. Using a combination of nuc gene PCR, MALDI-TOF-MS and sequencing of the tuf gene, 399 isolates $(92 \%, 95 \%$ CI 88.5, 93.8) were identified to the species level. MALDI-TOF-MS identified 345 isolates to the species level including 264 of 334 CoNS isolates $(79 \%, 95 \%$ CI $74.4,83.1)$. Amplification and sequencing of the tuf gene identified 33 out of 51 CoNS isolates $(65 \%, 95 \%$ CI $51,76.4)$ to the species level ( $\mathrm{n}=11$ species; $\geq 98 \%$ sequence similarity) and an additional control group $(n=27)$ of CoNS isolates that had also been identified by MALDI-TOF-MS. There was $100 \%$ agreement between the two methods for the identification of the control group. In particular, sequencing of the tuf gene identified all of the S. fleurettii, S. arlettae and $S$. pettenkoferi isolates, 12 isolates closely related to 


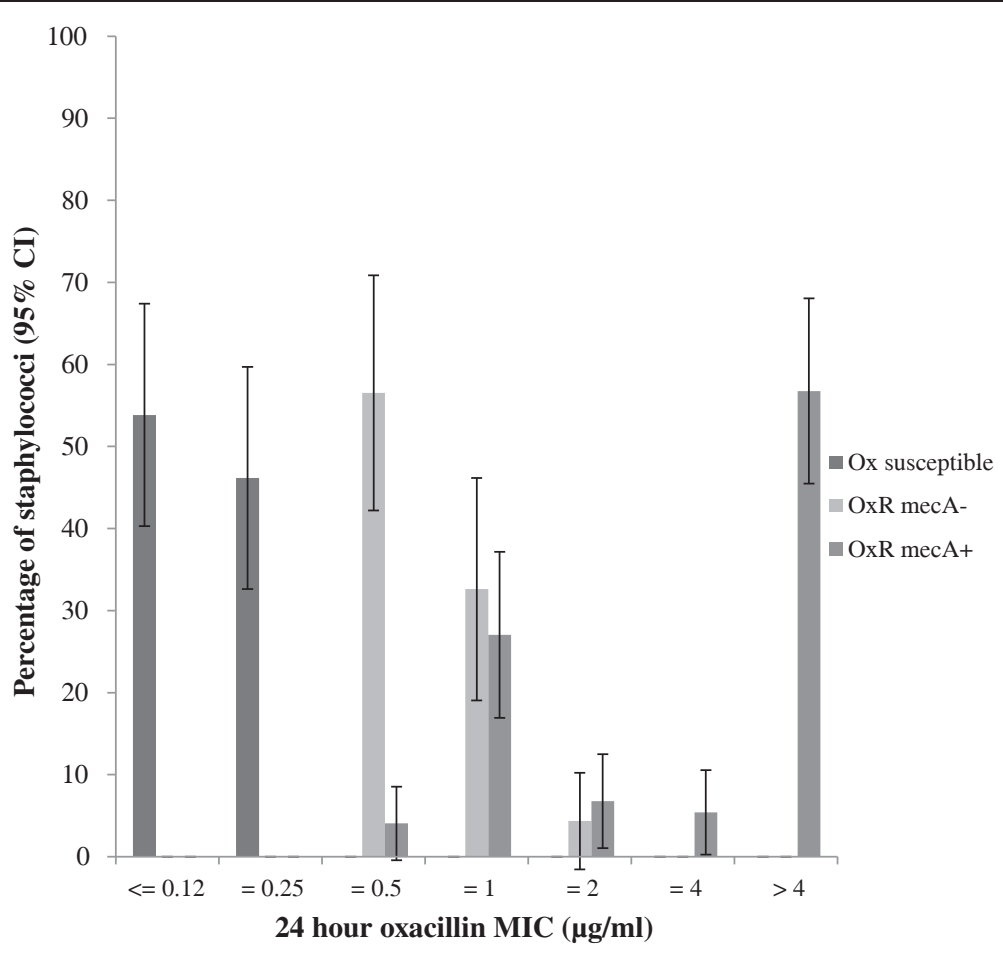

Figure 2 The MIC $(\boldsymbol{\mu g} / \mathrm{ml})$ data for staphylococcal isolates $(\mathbf{n}=\mathbf{1 7 2})$. The isolates consisted of 52 oxacillin susceptible isolates, 46 oxacillin resistant mecA negative isolates and 74 oxacillin resistant mecA positive isolates.

S. felis (96\% sequence similarity) and an additional 15 isolates to the genus level (Staphylococcus spp. $\geq 98 \%$ sequence similarity). PCR amplification of the $n u c$ gene detected all of the $S$. aureus $\mathrm{n}=11(100 \%, 95 \%$ CI 74.1 , $100)$ and S. pseudintermedius isolates $\mathrm{n}=91(100 \%, 95 \%$ CI 96.0, 100). There was $100 \%$ agreement of this assay with MALDI-TOF-MS for the identification of $S$. aureus isolates, however MALDI-TOF-MS only identified 69 out of $91 \mathrm{~S}$. pseudintermedius isolates.

Overall from the combined results using PCR amplification of the nuc gene, MALDI-TOF-MS and sequencing of the tuf gene we detected S. epidermidis in 52\% (95\% CI 41, 63) and S. pseudintermedius in 44\% (95\% CI $33,55)$ of the dogs. S. warneri and S. equorum were the

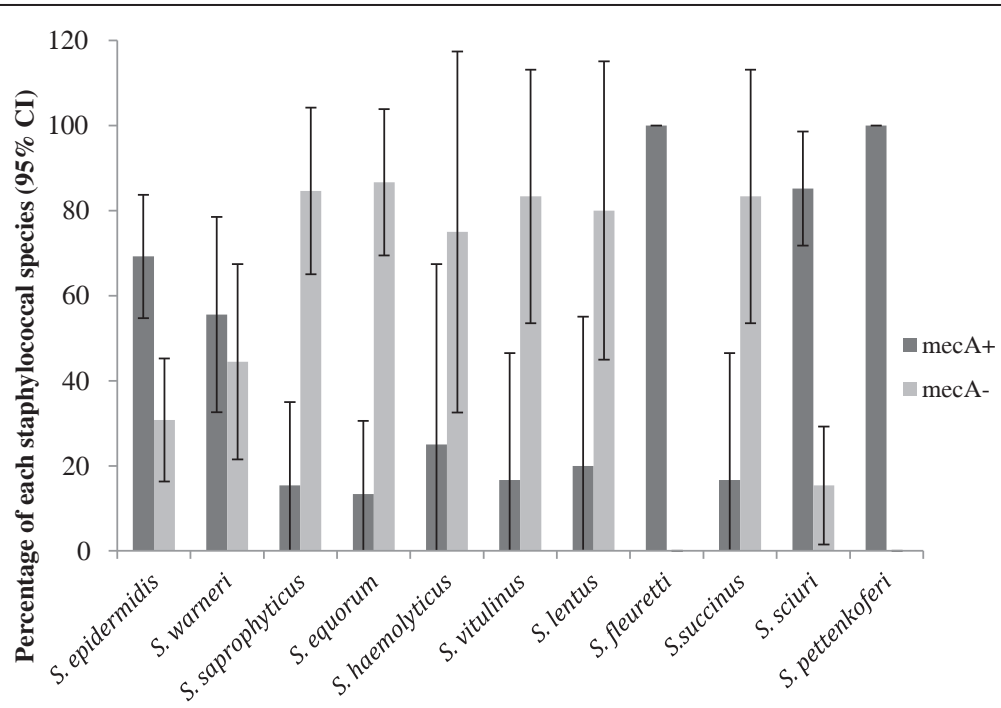

Figure 3 The percentage of each oxacillin-resistant staphylococcal species by disc diffusion and MIC that was either positive (mecA+) or negative (mecA-) for the mecA gene. 
next most common species, isolated from $30 \%$ and $27 \%$ of dogs respectively, and the remaining staphylococcal species were carried by no more than $15 \%$ of the dogs. $S$. aureus was detected in 6 of the dogs, exclusively from the nasal mucosae, and usually with S. pseudintermedius (88\%, 95\% CI 52.9, 97.8). S. pseudintermedius was concurrently isolated with 16 different CoNS species, although there was no significant association between the presence of S. pseudintermedius and any CoNS species (Pearson's chi-square; $P<0.003$ ) (Figure 4 and Table 3 ).

\section{Discussion}

This is the first study incorporating MALDI-TOF-MS to successfully characterise commensal staphylococcal populations in a group of healthy dogs in the absence of antimicrobial pressure. We isolated staphylococci from $99 \%$ of our dogs, with $95 \%$ carrying CoNS and $47 \%$ carrying CoPS. The relative prevalence of the staphylococci concurs with other published studies in humans [2,3], horses [63-67] and dogs [15,17,68], although the overall staphylococcal prevalence was double that reported for healthy vet visiting dogs [15]. This could be related to the study population and techniques, as we sampled both the nose and the perineum to increase detection of CoPS $[12,13,68,69]$.

We were able to assign $92 \%$ of the staphylococcal isolates to 20 different species, including 18 CoNS. This is the first study to demonstrate such diversity in dogs, and carriage of this number of different species has only been previously reported for humans $[2,10,12,15,21-26,70]$. The

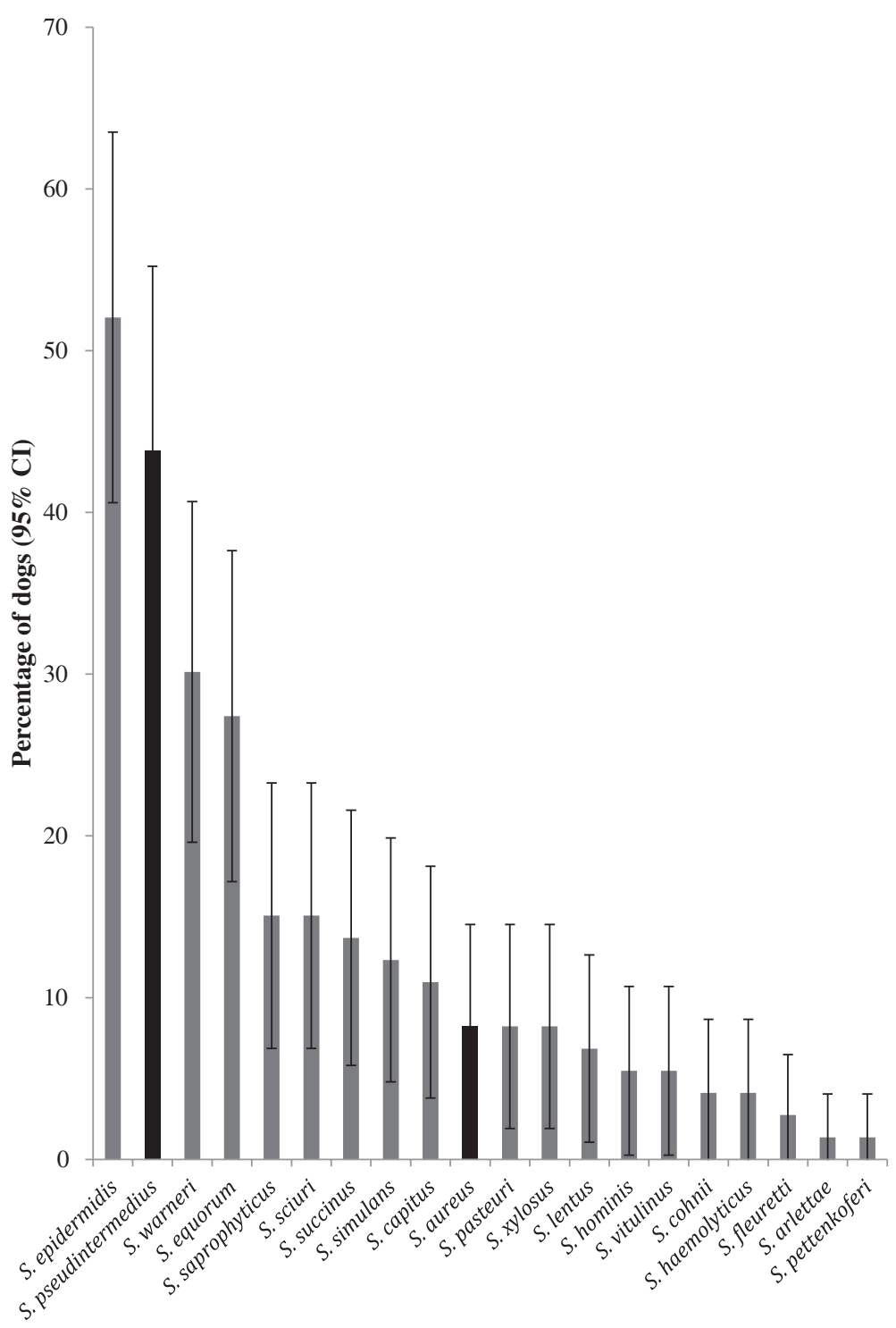

Figure 4 The percentage of dogs $(n=73$ ) carrying each staphylococcal species identified in this study by MALDI-TOF-MS, PCR of the nuc gene and sequencing of the tuf gene (CoNS grey and CoPS black). 
Table 3 The number of staphylococcal isolates identified to species level by MALDI-TOF-MS, nuc gene PCR (CoPS), and tuf gene sequencing

\begin{tabular}{|c|c|c|c|c|c|}
\hline Staphylococcal species & Number of isolates & $\begin{array}{l}\text { Number (\%) of } \\
\text { positive dogs }\end{array}$ & $\begin{array}{l}\text { Number (\%) identified by } \\
\text { MALDI-TOF-MS }\end{array}$ & $\begin{array}{l}\text { Number (\%) of CoPS } \\
\text { identified by nuc PCR }\end{array}$ & $\begin{array}{l}\text { Number (\%) identified } \\
\text { by tuf gene sequencing }\end{array}$ \\
\hline S. pseudintermedius & 91 & $32(44)$ & $70(77)$ & $91(100)$ & 0 \\
\hline S. aureus & 11 & $6(8)$ & $11(100)$ & $11(100)$ & 0 \\
\hline S. epidermidis & 67 & $38(52)$ & $64(96)$ & N/A & $3(4)$ \\
\hline S. warneri & 35 & $22(30)$ & $35(100)$ & N/A & 0 \\
\hline S. equorum & 39 & $20(27)$ & $36(92)$ & $\mathrm{N} / \mathrm{A}$ & $3(8)$ \\
\hline S. saprophyticus & 19 & $11(15)$ & $15(79)$ & N/A & $4(21)$ \\
\hline S. sciuri & 27 & $11(15)$ & $21(78)$ & N/A & $6(22)$ \\
\hline S. succinus & 19 & $10(14)$ & $16(84)$ & N/A & $3(16)$ \\
\hline S. simulans & 15 & $9(12)$ & $15(100)$ & N/A & 0 \\
\hline S. capitus & 7 & $8(11)$ & $7(100)$ & N/A & 0 \\
\hline S. pasteuri & 8 & $6(8)$ & $8(100)$ & N/A & 0 \\
\hline S. xylosus & 17 & $6(8)$ & $17(100)$ & N/A & 0 \\
\hline S. lentus & 9 & $5(7)$ & $4(44)$ & N/A & $5(56)$ \\
\hline S. hominis & 6 & $4(5)$ & $6(100)$ & $\mathrm{N} / \mathrm{A}$ & 0 \\
\hline S. cohnii & 5 & $3(4)$ & $3(60)$ & N/A & $2(40)$ \\
\hline S. vitulinus & 14 & $3(4)$ & $13(93)$ & N/A & $1(7)$ \\
\hline S. haemolyticus & 4 & $3(4)$ & $4(100)$ & N/A & 0 \\
\hline S. fleurettii & 4 & $2(3)$ & 0 & N/A & $4(100)$ \\
\hline S. arlettae & 1 & $1(1)$ & 0 & N/A & $1(100)$ \\
\hline S. pettenkoferi & 1 & $1(1)$ & 0 & N/A & $1(100)$ \\
\hline Total ID & $399^{d}$ & $72^{e}$ & $345^{f}$ & $101^{f}$ & $33^{f}$ \\
\hline Staphylococcus spp. & 3 & N/A & N/A & N/A & 3 \\
\hline Species related to S. felis & 12 & N/A & N/A & N/A & 12 \\
\hline No ID & 22 & N/A & N/A & 2 & 3 \\
\hline Total & $436^{\mathrm{a}}$ & $73^{b}$ & $436^{c}$ & $102^{c}$ & $51^{c}$ \\
\hline
\end{tabular}

Values in the table are expressed as total numbers and percentage in parenthesis where applicable. ${ }^{a}$ Total number of isolates in study, ${ }^{b}$ total number of dogs in

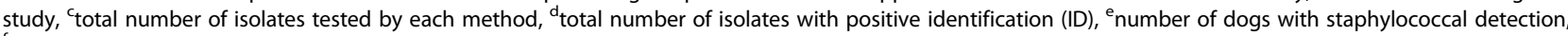
number of isolates with positive ID from each method.

most common species was $S$. epidermidis, which was detected in $52 \%$ of the dogs, mainly from the nasal cavity. This is similar to human reports [71], but apart from one canine study [23], S. epidermidis has not been commonly reported in different animal species $[67,72,73]$. S. pseudintermedius was the second most common species and the most common CoPS detected, also in agreement with previous reports [9-11,13]. Unlike S. epidermidis, $S$. pseudintermedius was carried equally in the nose and on the perineum, suggesting that this species may have a wider range of mucosal niches. Very few dogs carried S. aureus (8\%), which is comparable to other studies that reported carriage rates of approximately $7 \%$ from healthy vet visiting dogs $[12,15]$. The majority of the CoNS in our study were human-associated and included S. epidermidis, S. hominis, S. haemolyticus, S. capitus, S. saprophyticus, S. warneri, S. cohnii, S. simulans, S. pettenkoferi and S. pasteuri. Human associated CoNS species have previously been isolated from dogs, horses, cows and pigs $[23,67,72,74-76]$. The other CoNS species isolated from our dogs are reported as indigenous to animals ( $S$. equorum, S. vitulinus, S. arlettae S. sciuri, S. lentus and S. fleurettii) [2].

We used several methods to identify staphylococcal isolates to species level. Multiplex PCR for the $n u c$ gene is an accurate, rapid and cost efficient method to speciate CoPS [77], which identified $100 \%$ of our S. pseudintermedius $(\mathrm{n}=91)$ and $100 \%$ of our S. aureus isolates $(\mathrm{n}=11)$. Recently MALDI-TOF-MS has been reported as a rapid and reliable method to characterise CoNS, S. aureus and S. intermedius group (SIG) strains [59,72,78-80]. MALDITOF-MS identified all of our S. aureus isolates, $77 \%$ of our S. pseudintermedius isolates and $79 \%$ of our CoNS isolates, identified by phenotypic and biochemical characteristics, to the species level. Similar results for the identification of S. aureus, S. pseudintermedius and CoNS by 
MALDI-TOF-MS, in comparison to molecular methods, have been reported [79-81]. The overall performance of MALDI-TOF-MS to speciate the staphylococcal isolates in this study, similar to other reports [80], is likely to be directly related to the database, which at the time of analysis consisted mainly of common human-derived species and only one S. pseudintermedius strain. However species level identification will improve as more highly characterised reference isolates are added to the database. Amplification and sequencing of the tuf gene is regarded as the gold standard to speciate CoNS isolates $[59,60]$. This method identified $77 \%$ of the tested staphylococcal isolates $(n=79)$ to the species level. The performance of this method in our study may have been affected by the lack of certain-animal derived isolates representing different species in the database. Additionally, we may have improved identification by sequencing a larger region of the tuf gene. We sequenced a previously described 412 base pair region of the tuf gene that was reported to have successfully identified $88 \%$ of human-derived staphylococcal strains [60]. However, a more recent publication that sequenced a $660 \mathrm{bp}$ region of the tuf gene, reported 98.9\% identification of 186 human and animal-derived staphylococcal strains.

We did not detect any MR-CoPS isolates. Other studies of healthy dogs have similarly reported a low prevalence $[15,82,83]$. In contrast, $58 \%$ of the dogs in our study carried at least one CoNS isolate with phenotypic meticillin resistance and $42 \%$ carried a meticillin resistant mecA positive isolate. Other studies have also reported high levels of meticillin resistance among CoNS isolates from humans $[31,35,84]$, horses [23,64-66] and livestock [72,85]. However, the prevalence of MR-CoNS carriage in our study is markedly higher than the levels reported in other community canine studies $[15,23,50,74,83]$. High community carriage rates of MR-CoNS are of concern for animals and humans, as these organisms may not only be reservoirs of resistance genes for CoPS $[39,40,86]$, but also act as pathogens [31,36-38,87-89]. Cross-transmission is reported to be an important mechanism for dissemination of MRS [49,90], and transmission between dogs and in-contact humans may occur in the community and in veterinary premises $[36,83]$.

Nine different CoNS species carried the mecA gene in our study with MRSE detected in 25\% of our dogs. MRSE is the predominant MR-CoNS species in humans both in hospital and community settings $[39,48,49]$, and has been reported in one study investigating nasal carriage of MRS in dogs [23]. Other canine studies have isolated meticillin resistant S. sciuri and meticillin resistant $S$. warneri $[23,74]$. Our research found that the majority of the S. sciuri and S. fleurettii isolates were $m e c \mathrm{~A}$ positive, which is consistent with other studies in humans, livestock and horses $[35,64,66,67,72]$.
MDR CoNS ( $\mathrm{n}=38$ ) were isolated from $34 \%$ of dogs in this study. MDR was generally associated with resistance to $\beta$-lactams, FA and additional antimicrobials. In particular MDR-MRSE were resistant to at least four antimicrobial classes tested in our study. A similar finding was reported in a study of hospitalised animals, medical equipment and veterinary staff [68]. MDR among CoNS isolates is widely reported $[15,49,72,73,91]$ and may be associated with the carriage of multiple antimicrobial resistance genes on SCCmec cassettes [40]. In contrast, the majority of our commensal CoPS isolates were susceptible to a broad range of antimicrobials (apart from Tet), in line with previous reports for clinical isolates [92-94] and isolates from healthy vet-visiting dogs [15]. There was good to very good agreement between disc and MIC antimicrobial susceptibility testing apart for FC and CIP. These two antimicrobials were the only ones where human breakpoints were applied and emphasises potential species differences in pharmacokinetic and pharmacodynamic data for individual antimicrobials.

The mecA gene was not identified in $40 \%$ of the phenotypic oxacillin resistant isolates in this study and may include some isolate duplication due to our sampling methods. Other studies have reported phenotypic meticillin resistance with absence of the mecA gene in staphylococci [95-98]. Our OX-resistant mecA negative isolates may be truly negative for the mecA gene as they were less likely to be resistant to the other antimicrobials tested in this study, including CVN and CFX, and had significantly lower MICs compared to the OX resistant mecA positive isolates. It is possible that they had low-level resistance associated with other mechanisms such as hyperproduction of $\beta$-lactamases [99], or production of an oxacillin-specific $\beta$-lactamases [100]. There are bovine mastitis CoNS isolates with oxacillin MICs of $0.5-1 \mathrm{mg} / \mathrm{l}$ that lack the mecA gene [97], and the CLSI guidelines state that 'oxacillin interpretive criteria may overcall resistance for these CoNS strains' [57]. In addition, many of the published PCR assays to identify and characterise the mecA gene have been developed for MRSA [101-104] and may therefore lack sensitivity for some CoNS isolates. However, other authors have successfully employed the same methods for mecA detection among CoNS isolates as used in our study $[68,98,105]$. Nevertheless it is possible that additional PCR assay [106], or latex agglutination for PBP2a [107] may have improved the sensitivity of mecA detection or detected phenotypic mecA-associated resistance in our oxacillin resistant $m e c \mathrm{~A}$ negative isolates.

Our study had some limitations, including the small sample size. Still, these dogs yielded 436 staphylococcal isolates and a high prevalence of resistance was identified among the CoNS isolates even in the absence of antimicrobial exposure. Another weakness was that the study population was limited to one breed (Labrador 
retrievers) and the dogs were recruited at dog shows. Kennelled dogs have been shown to have higher levels of antimicrobial resistance in faecal $E$. coli than individually owned and non-kennelled dogs [108]. Kennelling was transient in our dogs, but this may have affected the results. Many of the dogs came from multi-dog households but only one dog from each household was sampled to avoid cluster effects.

\section{Conclusions}

This is the first comprehensive study of commensal staphylococcal populations in a group of healthy dogs. Staphylococci, particularly CoNS, form a normal part of the canine commensal population and were detected from almost all the dogs. The most commonly isolated staphylococcal species in this group of dogs was S. epidermidis, although a wide variety of other human- and animalassociated CoNS were found. CoPS were less common, and the major species was S. pseudintermedius. Antimicrobial resistance among the CoPS was uncommon, and no MRSP or MRSA were isolated, however the sample size was small. Antimicrobial resistance (including MDR and meticillin resistance) was common among the CoNS isolates, even though this was a community population of healthy dogs in the absence of direct-antimicrobial pressure or veterinary contact. The clinical significance of commensal CoNS and MR-CoNS is unclear, but S. epidermidis carries a number of virulence factors and is an increasing cause of nosocomial and community-acquired infections in humans. The possibility of similar infections escalating in companion animals cannot be excluded. In addition, there is potential for cross-species transmission of antimicrobial resistant bacteria and exchange of resistance determinants between bacterial species. In particular, MR- and MDRCoNS may provide a reservoir of antimicrobial resistance genes that could rapidly spread within bacterial populations under the selection pressure exerted by antimicrobial therapy. Further longitudinal studies in healthy dogs and in dogs receiving antimicrobials are required to assess the population diversity, antimicrobial resistance profiles and persistence of antimicrobial resistant staphylococci in dogs.

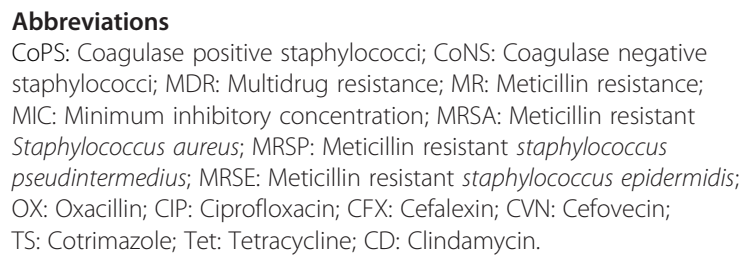

\section{Competing interests}

Vanessa Schmidt, Neil McEwan, Stephen Shaw and Tim Nuttall have received other unrelated funding from Zoetis (previously Pfizer Animal Health UK).

The authors declare that there are no financial or non-financial

competing interests.

\section{Authors' contributions}

VS was responsible for sample collection and processing, data analysis and writing the manuscript. NJW was responsible for advising on the microbiology methodology used in the study and interpretation of results and contributed to the writing of the manuscript. GP advised on statistical analysis. NM advised on ethical permission and sample collection and contributed to the writing of the manuscript. SS assisted sample collection and contributed to the writing of the manuscript. CEC was responsible for advising on and performing sequencing. SD advised on interpretation of results and contributed to the writing of the manuscript. TN advised on sample collection, interpretation of results and contributed to the writing of the manuscript. NW, GP, NM, SD and TN supervised VS during this project. All authors were involved in the design of this project and reviewed and approved the final manuscript.

\section{Acknowledgements}

The authors would like to thank Zoetis (previously Pfizer Animal Health) for funding this project, and Maureen D'Arcy and the North West and Midland Counties Labrador Retriever Clubs for allowing us to obtain samples. We would like to thank Erica Tranfield from Bruker (Liverpool, UK) for training and access to MALDI-TOF-MS Biotyper. We would also like to thank Ruth Ryvar and Gill Hutchinson for their technical support, Dorina Timofte and Andy Wattret for their technical advice, and Clara MacFarlane, Atina Unwin and Camilla Brena for their help in sample collection.

\section{Author details}

'Department of Infection Biology, The University of Liverpool, Leahurst Campus, Neston, UK. ${ }^{2}$ Department of Epidemiology and Population Health, The University of Liverpool, Leahurst Campus, Neston, UK. Infection and Immunity, Royal Liverpool University Hospital, Liverpool, UK. 'UK VetDerm, Coalville, UK. ${ }^{5}$ The Royal (Dick) School of Veterinary Studies, Easter Bush Campus, University of Edinburgh, Midlothian, UK. ${ }^{6}$ The University of Liverpool School of Veterinary Science, Leahurst Campus, Chester High Road, Neston, Wirral CH64 7TE, UK.

Received: 19 April 2013 Accepted: 6 January 2014

Published: 14 January 2014

\section{References}

1. Kloos WE: Natural populations of the genus Staphylococcus. Annu Rev Microbiol 1980, 34:559-592.

2. Kloos WE, Bannerman TL: Update on clinical significance of coagulasenegative staphylococci. Clin Microbiol Rev 1994, 7(1):117-140.

3. von Eiff $C$, Peters $G$, Heilmann C: Pathogenesis of infections due to coagulase-negative staphylococci. Lancet Infect Dis 2002, 2(11):677-685.

4. Rich M: Staphylococci in animals: prevalence, identification and antimicrobial susceptibility, with an emphasis on methicillin-resistant Staphylococcus aureus. Br J Biomed Sci 2005, 62(2):98-105.

5. Devriese LA, Vancanneyt M, Baele M, Vaneechoutte M, De Graef E, Snauwaert C, Cleenwerck I, Dawyndt P, Swings J, Decostere A, et al: Staphylococcus pseudintermedius sp. nov., a coagulase-positive species from animals. Int J Syst Evol Microbiol 2005, 55(Pt 4):1569-1573.

6. Mainous AG 3rd, Hueston WJ, Everett CJ, Diaz VA: Nasal carriage of Staphylococcus aureus and methicillin-resistant $S$ aureus in the United States, 2001-2002. Ann Fam Med 2006, 4(2):132-137.

7. Huebner J, Goldmann DA: Coagulase-negative staphylococci: role as pathogens. Annu Rev Med 1999, 50:223-236.

8. Mason IS, Mason KV, Lloyd DH: A review of the biology of canine skin with respect to the commensals Staphylococcus intermedius, Demodex canis and Malassezia pachydermatis. Vet Dermatol 1996, 7(3):119-132.

9. Devriese LA, De Pelsmaecker $K$ : The anal region as a main carrier site of Staphylococcus intermedius and Streptococcus canis in dogs. Vet Rec 1987, 121(13):302-303.

10. Griffeth GC, Morris DO, Abraham JL, Shofer FS, Rankin SC: Screening for skin carriage of methicillin-resistant coagulase-positive staphylococci and Staphylococcus schleiferi in dogs with healthy and inflamed skin. Vet Dermatol 2008, 19(3):142-149.

11. Hanselman BA, Kruth SA, Rousseau J, Weese JS: Coagulase positive staphylococcal colonization of humans and their household pets. Can Vet J 2009, 50(9):954-958. 
12. Fazakerley J, Williams N, Carter S, McEwan N, Nuttall T: Heterogeneity of Staphylococcus pseudintermedius isolates from atopic and healthy dogs. Vet Dermatol 2010, 21(6):578-585.

13. Rubin JE, Ball KR, Chirino-Trejo M: Antimicrobial susceptibility of Staphylococcus aureus and Staphylococcus pseudintermedius isolated from various animals. Can Vet J 2011, 52(2):153-157.

14. Paul NC, Bargman SC, Moodley A, Nielsen SS, Guardabassi L: Staphylococcus pseudintermedius colonisation patterns and strain diversity in healthy dogs: a cross-sectional and longitudinal study. Vet Microbiol 2012, 160(3-4):420-427.

15. Wedley AL: Prevalence of Staphyococcus spp. carriage in dogs. Department of Epidemiology and Population Health, Institute of Infection and Global Health, University of Liverpool; 2012

16. Pinchbeck LR, Cole LK, Hillier A, Kowalski JJ, Rajala-Schultz PJ, Bannerman TL, York S: Genotypic relatedness of staphylococcal strains isolated from pustules and carriage sites in dogs with superficial bacterial folliculitis. Am J Vet Res 2006, 67(8):1337-1346.

17. Loeffler A, Boag AK, Sung J, Lindsay JA, Guardabassi L, Dalsgaard A, Smith H, Stevens KB, Lloyd DH: Prevalence of methicillin-resistant Staphylococcus aureus among staff and pets in a small animal referral hospital in the UK. J Antimicrob Chemother 2005, 56(4):692-697.

18. Boost MV, O'Donoghue MM, Siu KH: Characterisation of methicillinresistant Staphylococcus aureus isolates from dogs and their owners. Clin Microbiol Infect 2007, 13(7):731-733.

19. Sasaki T, Kikuchi K, Tanaka Y, Takahashi N, Kamata S, Hiramatsu K: Reclassification of phenotypically identified Staphylococcus intermedius strains. J Clin Microbiol 2007, 45(9):2770-2778.

20. Kottler S, Middleton JR, Perry J, Weese JS, Cohn LA: Prevalence of Staphylococcus aureus and methicillin-resistant Staphylococcus aureus carriage in three populations. J Vet Intern Med 2010, 24(1):132-139.

21. Yamashita K, Shimizu A, Kawano J, Uchida E, Haruna A, Igimi S: Isolation and characterization of staphylococci from external auditory meatus of dogs with or without otitis externa with special reference to Staphylococcus schleiferi subsp. coagulans isolates. J Vet Med Sci 2005, 67(3):263-268.

22. May ER, Hnilica KA, Frank LA, Jones RD, Bemis DA: Isolation of Staphylococcus schleiferi from healthy dogs and dogs with otitis, pyoderma, or both. J Am Vet Med Assoc 2005, 227(6):928-931.

23. Bagcigil FA, Moodley A, Baptiste KE, Jensen VF, Guardabassi L: Occurrence, species distribution, antimicrobial resistance and clonality of methicillinand erythromycin-resistant staphylococci in the nasal cavity of domestic animals. Vet Microbio/ 2007, 121(3-4):307-315.

24. Kania SA, Williamson NL, Frank LA, Wilkes RP, Jones RD, Bemis DA: Methicillin resistance of staphylococci isolated from the skin of dogs with pyoderma. Am J Vet Res 2004, 65(9):1265-1268.

25. Medleau L, Long RE, Brown J, Miller WH: Frequency and antimicrobial susceptibility of Staphylococcus species isolated from canine pyodermas. Am J Vet Res 1986, 47(2):229-231.

26. Cox HU, Hoskins JD, Newman SS, Foil CS, Turnwald GH, Roy AF: Temporal study of staphylococcal species on healthy dogs. Am J Vet Res 1988, 49(6):747-751.

27. Bannoehr J, Guardabassi L: Staphylococcus pseudintermedius in the dog: taxonomy, diagnostics, ecology, epidemiology and pathogenicity. Vet Dermatol 2012, 23(4):253-266. e251-252.

28. Hartman BJ, Tomasz A: Low-affinity penicillin-binding protein associated with beta-lactam resistance in Staphylococcus aureus. J Bacteriol 1984, 158(2):513-516.

29. Black CC, Solyman SM, Eberlein LC, Bemis DA, Woron AM, Kania SA: Identification of a predominant multilocus sequence type, pulsed-field gel electrophoresis cluster, and novel staphylococcal chromosomal cassette in clinical isolates of mecA-containing, methicillin-resistant Staphylococcus pseudintermedius. Vet Microbiol 2009, 139(3-4):333-338.

30. Hryniewicz W: Epidemiology of MRSA. Infection 1999, 27(Suppl 2):S13-S16

31. Diekema DJ, Pfaller MA, Schmitz FJ, Smayevsky J, Bell J, Jones RN, Beach M: Survey of infections due to Staphylococcus species: frequency of occurrence and antimicrobial susceptibility of isolates collected in the United States, Canada, Latin America, Europe, and the Western Pacific region for the SENTRY Antimicrobial Surveillance Program, 1997-1999. Clin Infect Dis 2001, 32(Suppl 2):S114-S132.

32. Loeffler A, Linek M, Moodley A, Guardabassi L, Sung JM, Winkler M, Weiss R, Lloyd DH: First report of multiresistant, mecA-positive Staphylococcus intermedius in Europe: 12 cases from a veterinary dermatology referral clinic in Germany. Vet Dermatol 2007, 18(6):412-421.

33. Weese JS, van Duijkeren E: Methicillin-resistant Staphylococcus aureus and Staphylococcus pseudintermedius in veterinary medicine. Vet Microbiol 2010, 140(3-4):418-429.

34. Perreten V, Kadlec K, Schwarz S, Gronlund Andersson U, Finn M, Greko C, Moodley A, Kania SA, Frank LA, Bemis DA, et al: Clonal spread of methicillin-resistant Staphylococcus pseudintermedius in Europe and North America: an international multicentre study. J Antimicrob Chemother 2010, 65(6):1145-1154

35. Garza-Gonzalez E, Morfin-Otero R, Martinez-Vazquez MA, Gonzalez-Diaz E, Gonzalez-Santiago O, Rodriguez-Noriega E: Microbiological and molecular characterization of human clinical isolates of Staphylococcus cohnii, Staphylococcus hominis, and Staphylococcus sciuri. Scand J Infect Dis 2011, 43(11-12):930-936.

36. van Duijkeren E, Kamphuis M, van der Mije IC, Laarhoven LM, Duim B, Wagenaar JA, Houwers DJ: Transmission of methicillin-resistant Staphylococcus pseudintermedius between infected dogs and cats and contact pets, humans and the environment in households and veterinary clinics. Vet Microbiol 2011, 150(3-4):338-343.

37. Hauschild T, Wojcik A: Species distribution and properties of staphylococci from canine dermatitis. Res Vet Sci 2007, 82(1):1-6.

38. Kern A, Perreten $\mathrm{V}$ : Clinical and molecular features of methicillin-resistant, coagulase-negative staphylococci of pets and horses. J Antimicrob Chemother 2013, 68(6):1256-1266.

39. Barbier F, Ruppe E, Hernandez D, Lebeaux D, Francois P, Felix B, Desprez A, Maiga A, Woerther PL, Gaillard K, et al: Methicillin-resistant coagulasenegative staphylococci in the community: high homology of SCCmec IVa between Staphylococcus epidermidis and major clones of methicillinresistant Staphylococcus aureus. J Infect Dis 2010, 202(2):270-281.

40. Smyth DS, Wong A, Robinson DA: Cross-species spread of SCCmec IV subtypes in staphylococci. Infect Genet Evol 2011, 11(2):446-453.

41. Descloux S, Rossano A, Perreten V: Characterization of new staphylococcal cassette chromosome mec ( $\mathrm{SCCmec}$ ) and topoisomerase genes in fluoroquinolone- and methicillin-resistant Staphylococcus pseudintermedius. J Clin Microbiol 2008, 46(5):1818-1823.

42. Abudu L, Blair I, Fraise A, Cheng KK: Methicillin-resistant Staphylococcus aureus (MRSA): a community-based prevalence survey. Epidemiol Infect 2001, 126(3):351-356.

43. Shopsin B, Mathema B, Martinez J, Ha E, Campo ML, Fierman A, Krasinski K, Kornblum J, Alcabes P, Waddington M, et al: Prevalence of methicillinresistant and methicillin-susceptible Staphylococcus aureus in the community. J Infect Dis 2000, 182(1):359-362.

44. Maudsley J, Stone SP, Kibbler CC, Iliffe SR, Conaty SJ, Cookson BD, Duckworth GJ, Johnson A, Wallace PG: The community prevalence of methicillin-resistant Staphylococcus aureus (MRSA) in older people living in their own homes: implications for treatment, screening and surveillance in the UK. J Hosp Infect 2004, 57(3):258-262.

45. Sa-Leao R, Sanches IS, Couto I, Alves CR, de Lencastre H: Low prevalence of methicillin-resistant strains among Staphylococcus aureus colonizing young and healthy members of the community in Portugal. Microb Drug Resist 2001, 7(3):237-245.

46. Zanelli G, Sansoni A, Zanchi A, Cresti S, Pollini S, Rossolini GM, Cellesi C: Staphylococcus aureus nasal carriage in the community: a survey from central Italy. Epidemiol Infect 2002, 129(2):417-420.

47. Loeffler A, Pfeiffer DU, Lindsay JA, Magalhaes RJ, Lloyd DH: Prevalence of and risk factors for MRSA carriage in companion animals: a survey of dogs, cats and horses. Epidemiol Infect 2010:1-10.

48. Lebeaux D, Barbier F, Angebault C, Benmahdi L, Ruppe E, Felix B, Gaillard K, Djossou F, Epelboin L, Dupont C, et al: Evolution of nasal carriage of methicillin-resistant coagulase-negative staphylococci in a remote population. Antimicrob Agents Chemother 2012, 56(1):315-323.

49. Silva FR, Mattos EM, Coimbra MV, Ferreira-Carvalho BT, Figueiredo AM: Isolation and molecular characterization of methicillin-resistant coagulase-negative staphylococci from nasal flora of healthy humans at three community institutions in Rio de Janeiro City. Epidemiol Infect 2001, 127(1):57-62.

50. Vengust M, Anderson ME, Rousseau J, Weese JS: Methicillin-resistant staphylococcal colonization in clinically normal dogs and horses in the community. Lett Appl Microbiol 2006, 43(6):602-606.

51. Nienhoff U, Kadlec K, Chaberny IF, Verspohl J, Gerlach GF, Kreienbrock L, Schwarz S, Simon D, Nolte I: Methicillin-resistant Staphylococcus 
pseudintermedius among dogs admitted to a small animal hospital. Vet Microbiol 2011, 150(1-2):191-197.

52. Bergstrom A, Gustafsson C, Leander M, Fredriksson M, Gronlund U, Trowald-Wigh G: Occurrence of methicillin-resistant staphylococci in surgically treated dogs and the environment in a Swedish animal hospital. J Small Anim Pract 2012, 53(7):404-410.

53. Huerta B, Maldonado A, Ginel PJ, Tarradas C, Gomez-Gascon L, Astorga RJ, Luque I: Risk factors associated with the antimicrobial resistance of staphylococci in canine pyoderma. Vet Microbiol 2011, 150(3-4):302-308.

54. CLSI (Ed): Performance Standards for Antimicrobial Disk and Dilution Susceptibility Tests for Bacteria Isolated From Animals; Approved StandardThird Edition. CLSI document M31-A3. Wayne, PA: Clinical and Laboratory Standards Institute; 2008

55. EUCAST: Breakpoint tables for interpretation of MICs and zone diameters. Version 3.1, 2013. http://www.eucast.org.

56. Bemis DA, Jones RD, Frank LA, Kania SA: Evaluation of susceptibility test breakpoints used to predict mecA-mediated resistance in Staphylococcus pseudintermedius isolated from dogs. J Vet Diagn Invest 2009, 21(1):53-58.

57. CLSI (Ed): Performance standards for antimicrobial disk and dilution susceptibility tests for bacteria isolated from animals; Approved Standard Fourth Edition. CLSI document VET01-A. Wayne, PA: Clinical and Laboratory Standards Institute; 2013.

58. Alatoom AA, Cunningham SA, Ihde SM, Mandrekar J, Patel R: Comparison of direct colony method versus extraction method for identification of gram-positive cocci by use of Bruker Biotyper matrix-assisted laser desorption ionization-time of flight mass spectrometry. J Clin Microbiol 2011, 49(8):2868-2873.

59. Carpaij N, Willems RJ, Bonten MJ, Fluit AC: Comparison of the identification of coagulase-negative staphylococci by matrix-assisted laser desorption ionization time-of-flight mass spectrometry and tuf sequencing. Eur J Clin Microbiol Infect Dis 2011, 30(10):1169-1172.

60. Heikens E, Fleer A, Paauw A, Florijn A, Fluit AC: Comparison of genotypic and phenotypic methods for species-level identification of clinical isolates of coagulase-negative staphylococci. J Clin Microbiol 2005, 43(5):2286-2290

61. Altschul SF, Gish W, Miller W, Myers EW, Lipman DJ: Basic local alignment search tool. J Mol Biol 1990, 215(3):403-410.

62. Landis JR, Koch GG: Measurement of observer agreement for categorical data. Biometrics 1977, 33(1):159-174.

63. Yasuda R, Kawano J, Onda H, Takagi M, Shimizu A, Anzai T: Methicillinresistant coagulase-negative staphylococci isolated from healthy horses in Japan. Am J Vet Res 2000, 61(11):1451-1455.

64. Busscher JF, van Duijkeren E, Sloet van Oldruitenborgh-Oosterbaan MM: The prevalence of methicillin-resistant staphylococci in healthy horses in the Netherlands. Vet Microbio/ 2006, 113(1-2):131-136.

65. Moodley A, Guardabassi L: Clonal spread of methicillin-resistant coagulase-negative staphylococci among horses, personnel and environmental sites at equine facilities. Vet Microbio/ 2009, 137(3-4):397-401.

66. De Martino L, Lucido M, Mallardo K, Facello B, Mallardo M, lovane G, Pagnini U, Tufano MA, Catalanotti P: Methicillin-resistant staphylococci isolated from healthy horses and horse personnel in Italy. J Vet Diagn Invest 2010, 22(1):77-82

67. Karakulska J, Fijalkowski K, Nawrotek P, Pobucewicz A, Poszumski F, Czernomysy-Furowicz D: Identification and methicillin resistance of coagulase-negative staphylococci isolated from nasal cavity of healthy horses. J Microbiol 2012, 50(3):444-451.

68. Moon BY, Youn JH, Shin S, Hwang SY, Park YH: Genetic and phenotypic characterization of methicillin-resistant staphylococci isolated from veterinary hospitals in South Korea. J Vet Diagn Invest 2012, 24(3):489-498.

69. Windahl U, Reimegard E, Holst BS, Egenvall A, Fernstrom L, Fredriksson M, Trowald-Wigh G, Andersson UG: Carriage of methicillin-resistant Staphylococcus pseudintermedius in dogs-a longitudinal study. BMC Vet Res 2012, 8:34.

70. Widerstrom M, Wistrom J, Sjostedt A, Monsen T: Coagulase-negative staphylococci: update on the molecular epidemiology and clinical presentation, with a focus on Staphylococcus epidermidis and Staphylococcus saprophyticus. Eur J Clin Microbiol Infect Dis 2012, 31(1):7-20.

71. Rogers KL, Fey PD, Rupp ME: Coagulase-negative staphylococcal infections. Infect Dis Clin North Am 2009, 23(1):73-98.

72. Huber H, Ziegler D, Pfluger V, Vogel G, Zweifel C, Stephan R: Prevalence and characteristics of methicillin-resistant coagulase-negative staphylococci from livestock, chicken carcasses, bulk tank milk, minced meat, and contact persons. BMC Vet Res 2011, 7:6.

73. Garbacz K, Zarnowska S, Piechowicz L, Haras K: Staphylococci isolated from carriage sites and infected sites of dogs as a reservoir of multidrug resistance and methicillin resistance. Curr Microbio/ 2013, 66(2):169-173.

74. Malik S, Coombs GW, O'Brien FG, Peng H, Barton MD: Molecular typing of methicillin-resistant staphylococci isolated from cats and dogs. J Antimicrob Chemother 2006, 58(2):428-431.

75. Gillespie BE, Headrick SI, Boonyayatra S, Oliver SP: Prevalence and persistence of coagulase-negative Staphylococcus species in three dairy research herds. Vet Microbio/ 2009, 134(1-2):65-72.

76. Tulinski P, Fluit AC, Wagenaar JA, Mevius D, van de Vijver L, Duim B: Methicillin-resistant coagulase-negative staphylococci on pig farms as a reservoir of heterogeneous staphylococcal cassette chromosome mec elements. Appl Environ Microbiol 2012, 78(2):299-304.

77. Sasaki T, Tsubakishita S, Tanaka Y, Sakusabe A, Ohtsuka M, Hirotaki S, Kawakami T, Fukata T, Hiramatsu K: Multiplex-PCR method for species identification of coagulase-positive staphylococci. J Clin Microbiol 2010, 48(3):765-769.

78. Dubois D, Leyssene D, Chacornac JP, Kostrzewa M, Schmit PO, Talon R, Bonnet R, Delmas J: Identification of a variety of Staphylococcus species by matrix-assisted laser desorption ionization-time of flight mass spectrometry. J Clin Microbiol 2010, 48(3):941-945.

79. Szabados F, Woloszyn J, Richter C, Kaase M, Gatermann S: Identification of molecularly defined Staphylococcus aureus strains using matrix-assisted laser desorption/ionization time of flight mass spectrometry and the Biotyper 2.0 database. J Med Microbiol 2010, 59(Pt 7):787-790.

80. Decristophoris P, Fasola A, Benagli C, Tonolla M, Petrini O: Identification of Staphylococcus intermedius Group by MALDI-TOF MS. Syst Appl Microbiol 2011, 34(1):45-51.

81. Bergeron M, Dauwalder $\mathrm{O}$, Gouy M, Freydiere AM, Bes M, Meugnier $H$, Benito $Y$, Etienne J, Lina G, Vandenesch F, et al: Species identification of staphylococci by amplification and sequencing of the tuf gene compared to the gap gene and by matrix-assisted laser desorption ionization time-of-flight mass spectrometry. Eur J Clin Microbiol Infect Dis 2011, 30(3):343-354.

82. Onuma K, Tanabe T, Sato H: Antimicrobial resistance of Staphylococcus pseudintermedius isolates from healthy dogs and dogs affected with pyoderma in Japan. Vet Dermatol 2012, 23(1):17-22. e15.

83. Vanderhaeghen W, Van de Velde E, Crombe F, Polis I, Hermans K, Haesebrouck F, Butaye P: Screening for methicillin-resistant staphylococci in dogs admitted to a veterinary teaching hospital. Res Vet Sci 2012, 93(1):133-136

84. Hanssen AM, Ericson Sollid JU: SCCmec in staphylococci: genes on the move. FEMS Immunol Med Microbiol 2006, 46(1):8-20

85. Zhang Y, Agidi S, LeJeune JT: Diversity of staphylococcal cassette chromosome in coagulase-negative staphylococci from animal sources. J Appl Microbiol 2009, 107(4):1375-1383.

86. Tsubakishita S, Kuwahara-Arai K, Sasaki T, Hiramatsu K: Origin and molecular evolution of the determinant of methicillin resistance in staphylococci. Antimicrob Agents Chemother 2010, 54(10):4352-4359.

87. Duval $X$, Selton-Suty C, Alla F, Salvador-Mazeng M, Bernard Y, Weber M, Lacassin F, Nazeyrolas P, Chidiac C, Hoen B, et al: Endocarditis in patients with a permanent pacemaker: a 1-year epidemiological survey on infective endocarditis due to valvular and/or pacemaker infection. Clin Infect Dis 2004, 39(1):68-74.

88. Moran E, Masters S, Berendt AR, McLardy-Smith P, Byren I, Atkins BL: Guiding empirical antibiotic therapy in orthopaedics: the microbiology of prosthetic joint infection managed by debridement, irrigation and prosthesis retention. J Infect 2007, 55(1):1-7.

89. Piette A, Verschraegen $\mathrm{G}$ : Role of coagulase-negative staphylococci in human disease. Vet Microbio/ 2009, 134(1-2):45-54.

90. Cimiotti JP, Wu F, Della-Latta P, Nesin M, Larson E: Emergence of resistant staphylococci on the hands of new graduate nurses. Infect Control Hosp Epidemiol 2004, 25(5):431-435.

91. Wisplinghoff $H$, Bischoff $T$, Tallent SM, Seifert $H$, Wenzel RP, Edmond MB: Nosocomial bloodstream infections in US hospitals: analysis of 24,179 cases from a prospective nationwide surveillance study. Clin Infect Dis 2004, 39(3):309-317.

92. Lloyd DH, Lamport Al, Feeney C: Sensitivity to antibiotics amongst cutaneous and mucosal isolates of canine pathogenic staphylococci in the UK, 1980-96. Vet Dermatol 1996, 7:171-175. 
93. Kruse H, Hofshagen M, Thoresen SI, Bredal WP, Vollset I, Soli NE: The antimicrobial susceptibility of Staphylococcus species isolated from canine dermatitis. Vet Res Commun 1996, 20(3):205-214.

94. Hoekstra KA, Paulton RJ: Clinical prevalence and antimicrobial susceptibility of Staphylococcus aureus and Staphylococcus intermedius in dogs. J Appl Microbiol 2002, 93(3):406-413.

95. Suzuki E, Hiramatsu K, Yokota T: Survey of methicillin-resistant clinical strains of coagulase-negative staphylococci for mecA gene distribution. Antimicrob Agents Chemother 1992, 36(2):429-434.

96. Bignardi GE, Woodford N, Chapman A, Johnson AP, Speller DC: Detection of the mec-A gene and phenotypic detection of resistance in Staphylococcus aureus isolates with borderline or low-level methicillinresistance. J Antimicrob Chemother 1996, 37(1):53-63.

97. Fessler AT, Billerbeck C, Kadlec K, Schwarz S: Identification and characterization of methicillin-resistant coagulase-negative staphylococci from bovine mastitis. J Antimicrob Chemother 2010, 65(8):1576-1582.

98. Eckholm NG, Outerbridge CA, White SD, Sykes JE: Prevalence of and risk factors for isolation of meticillin-resistant Staphylococcus spp. from dogs with pyoderma in northern California, USA. Vet Dermatol 2013, 24(1):154-161. e134

99. Rosdahl VT, Rosendal K: Correlation of penicillinase production with phage type and susceptibility to antibiotics and heavy metals in Staphylococcus aureus. J Med Microbiol 1983, 16(4):391-399.

100. Jones RD, Kania SA, Rohrbach BW, Frank LA, Bemis DA: Prevalence of oxacillin- and multidrug-resistant staphylococci in clinical samples from dogs: 1,772 samples (2001-2005). J Am Vet Med Assoc 2007, 230(2):221-227.

101. Mehrotra M, Wang G, Johnson WM: Multiplex PCR for detection of genes for Staphylococcus aureus enterotoxins, exfoliative toxins, toxic shock syndrome toxin 1, and methicillin resistance. J Clin Microbiol 2000, 38(3):1032-1035.

102. Zhang K, McClure JA, Elsayed S, Louie T, Conly JM: Novel multiplex PCR assay for characterization and concomitant subtyping of staphylococcal cassette chromosome mec types I to V in methicillin-resistant Staphylococcus aureus. J Clin Microbiol 2005, 43(10):5026-5033.

103. Kondo Y, Ito T, Ma XX, Watanabe S, Kreiswirth BN, Etienne J, Hiramatsu K Combination of multiplex PCRs for staphylococcal cassette chromosome mec type assignment: rapid identification system for mec, $c \mathrm{cr}$, and major differences in junkyard regions. Antimicrob Agents Chemother 2007, 51(1):264-274

104. Francois P, Pittet D, Bento M, Pepey B, Vaudaux P, Lew D, Schrenzel J: Rapid detection of methicillin-resistant Staphylococcus aureus directly from sterile or nonsterile clinical samples by a new molecular assay. J Clin Microbiol 2003, 41(1):254-260.

105. Ruppe E, Barbier F, Mesli Y, Maiga A, Cojocaru R, Benkhalfat M, Benchouk S, Hassaine H, Maiga I, Diallo A, et al: Diversity of staphylococcal cassette chromosome mec structures in methicillin-resistant Staphylococcus epidermidis and Staphylococcus haemolyticus strains among outpatients from four countries. Antimicrob Agents Chemother 2009, 53(2):442-449.

106. Murakami K, Minamide W, Wada K, Nakamura E, Teraoka H, Watanabe S: Detection of methicillin-resistant Staphylococcus aureus by polymerase chain reaction. Rinsho Byori 1991, 39(12):1325-1330.

107. Baddour MM, AbuElKheir MM, Fatani AJ: Comparison of mecA polymerase chain reaction with phenotypic methods for the detection of methicillinresistant Staphylococcus aureus. Curr Microbiol 2007, 55(6):473-479.

108. De Graef EM, Decostere A, Devriese LA, Haesebrouck F: Antibiotic resistance among fecal indicator bacteria from healthy individually owned and kennel dogs. Microb Drug Resist 2004, 10(1):65-69.

doi:10.1186/1746-6148-10-17

Cite this article as: Schmidt et al:: Antimicrobial resistance and characterisation of staphylococci isolated from healthy Labrador retrievers in the United Kingdom. BMC Veterinary Research 2014 10:17.

\section{Submit your next manuscript to BioMed Central and take full advantage of:}

- Convenient online submission

- Thorough peer review

- No space constraints or color figure charges

- Immediate publication on acceptance

- Inclusion in PubMed, CAS, Scopus and Google Scholar

- Research which is freely available for redistribution

Submit your manuscript at www.biomedcentral.com/submit
Ciomed Central 